\title{
Constructive Voice Behavior for Social Change on Social Networking Sites: A Reflection of Moral Identity
}

\author{
Bhatti, Z.A. ${ }^{1}$, Arain, G.A. ${ }^{2}$, Akram, M.S. ${ }^{3}$, Fang, Y.H. ${ }^{4}$ and Yasin, H.M ${ }^{1}$ \\ ${ }^{1}$ Portsmouth Business School, University of Portsmouth, UK \\ ${ }^{2}$ College of Business \& Economics, United Arab Emirates University, UAE \\ ${ }^{3}$ Essex Business School, University of Essex, UK \\ ${ }^{4}$ Department of Accounting, Tamkang University, Taiwan
}

\begin{abstract}
Social networking sites (SNSs) have enabled people to voice their concerns by making their voices heard and hence initiate social change. Constructive voice behavior concerning societal matters, mediated by SNSs, is a much under-explored area and requires investigation. Primarily, voice literature has mainly discussed voice behavior within organizations focused on employees. However, individuals, as members of society, are using social media websites to voice about social change in the form of condemning harmful practices in society and/or promoting social good. Drawing from the self-consistency theory, this study explores the role of an individual's moral identity as an antecedent of constructive voice behavior on SNSs. Hierarchical multiple regression analysis results of 226 SNSs users, provide support to the self-consistency theory-based moderated-mediation model in which the positive relationships, between individual's moral identity and the promotive-prohibitive voice on SNSs, were mediated by the felt responsibility for constructive change (FOCC). Further, proactive personality moderates the positive mediation effect of FOCC between moral identity and prohibitive voice but not for promotive voice, such that the mediation effect would be stronger for individuals with a high-proactive personality than those of with a low-proactive personality. This study contributes to both voice and social media research in a number of ways.
\end{abstract}

Keywords: Social networking sites; constructive voice behavior; moral identity; felt obligation for constructive change; self-consistency theory; social change 


\section{Introduction}

Social networking sites (SNSs) are used by individuals for a wide range of social purposes by capitalizing on their social influene and sharing information online (Kizgin et al., 2018). SNSs have empowered users by handing them a global megaphone to speak directly to the world by making their voices heard and hence become agents initiating social change (Leetaru, 2018). Prior voice literature has mainly explored voice behavior within organizations. However, constructive voice behavior, concerning societal matters, mediated by SNSs is a much under-explored area and requires investigation. Constructive voice, which refers to one's discretional prosocial initiative of offering suggestions for change and raising concerns over practices that may harm one's place, ranging from a specific workplace to society, has mostly been studied in the organizational behavior (OB) literature (Morrison, 2014). Specifically, promotive and prohibitive forms of constructive voice, which refer to an employee's voluntary upward communication of (1) suggestions to bring change (i.e., promotive voice) and (2) concerns over potentially harmful practices and procedures (i.e., prohibitive voice) (Liang et al., 2012), have been associated with a wide range of individual, team, and organizational level positive outcomes, [c.f. (Chamberlin et al., 2017)]. The utility of such constructive voice behaviors is not only limited to bring about change in organizational work life but also extends to broader social work life, particularly using social media communication (Holland et al., 2016).

For instance, in June 2018, CEOs of many major companies such as Airbnb, Chobani, Cisco, Facebook, Google, and Uber exhibited prohibitive voice using the Internet to show concern over the US Government's "zero tolerance" policy on separating immigrant children from their parents who were arrested for crossing the US border illegally (Time's Magazine, 2018). To quote, for instance, the CEO of Airbnb tweeted that "ripping children from their parents' arms is heartless...and counter to the American values of belonging". Similarly, the CEO of Google wrote on his Twitter account, "the stories and images of families being separated at the border are gutwrenching. Urging our government to work together to find a better, more humane way that is reflective of our values as a nation". A Twitter and Facebook hashtag trend "\#keepfamiliestogether," in favor of immigrant families, started immediately following the news and millions of people across the globe made their voices heard online via the powerful platform of social media.

While famed people have a large number of social media followers and consequently their social media posts have high reachability, the general public is also capitalizing on the power of social media and making their voices heard on societal, environmental, and ethical matters to bring about social change (Leetaru, 2018). For example, in a recent event in December 2017, a black American citizen, in his Facebook post, sharing his picture and location, hilariously took down a racist woman while boarding a flight. The woman presuming that he is traveling in the economy class asked him to get out of the line of business-class travelers (News.com.au, 2017). In support, his post was re-shared thousands of times and even made the news condemning the very act of 
racism. People also use social media for exhibiting promotive voice in forms of textual posts, photos, and even making videos of events that promote social good in society. For instance, a heart-warming promotive post, about Mexican bakers making pan dulce for hundreds of trapped Harvey tropical storm victims, was shared by 2.4 Million Facebook users in 2017.

Within organizations, employees' voice is important for continuous improvement of organizations (Botero and Van Dyne, 2009), similarly people's voice about issues in society is vital for the advancement and betterment of society. One way how societies can improve themselves is via the feedback and suggestions given by their citizens about what is happening in their surroundings. Resce and Maynard (2018) argue that in today's world the largest collection of information regarding society exists on social media. Therefore, they carried out a study by extracting and analyzing tweets of people, living in OECD countries, which showed their concerns about better life index. The study showed people voiced about education, safety, environment, civic engagement, and work-life balance among many others. Since the use of social media for exhibiting such constructive voice has exponentially increased over the last decade (Martin et al., 2015) so, it is essential to understand why people exhibit (promotive and prohibitive forms of constructive) voice behavior on social media, which will be helpful for the betterment of society. Given that voice has been identified as a prosocial behavior in OB literature (Dyne and LePine, 1998), the investigation of factors that lead to prosocial motivation for exhibiting such prosocial behavior on social media would extend the voice literature beyond the OB literature. Thus, this study's contributions to the existing literatures on social media and voice is twofold.

First, prior voice literature has mainly explored employee voice behavior within organizations [e.g.,(Mowbray et al., 2015)]. While earlier studies focused on defining voice and identifying different forms of voice behaviors [e.g., (Aryee et al., 2017)], more recently researchers have focused on determinants [e.g., ( $\mathrm{Li}$ et al., 2017; Lin et al., 2017)] as well as on the consequences of voice behaviors in organizations. However, voicing mediated by social media communication has been primarily studied only in organizational work context [e.g., (Holland et al., 2016; Martin et al., 2015)] and has not yet been examined in the broader social life context. In addressing this research gap, this study examines moral identity, defined as an individual's "selfconception organized around a set of moral traits," such as friendly, fair, kind, caring, and hardworking (Aquino and Reed, 2002, p. 1424), as an antecedent of promotive and prohibitive voice behaviors on social media. Hu and Jiang (2018) note that individuals with high levels of moral identity are prone to recognize, and voice against violations of socio-moral values. Furthermore, moral identity is a strong predictor of prosocial behaviors (Aquino et al., 2009; Aquino and Reed, 2002). Considering, voice behavior as a prosocial behavior (Dyne and LePine, 1998) - since it focuses on constructive challenges rather than just criticizing -- we expect an individual's moral identity to be a predictor of his/her voice behavior on social media. Specifically, we expect that moral identity, being a largely stable psychological factor, can foster constructive 
voice behaviors more than the interpersonal and situational antecedents of constructive voice behaviors.

Second, understanding of the proposed relationship between moral identity and social media voicing would be incomplete without explaining the underlying motivational mechanism that explains this relationship. Since moral individuals tend to behave in a matter consistent with their self, they feel an obligation to engage in moral actions. "Felt obligation for constructive change" (FOCC) - defined by Liang et al. (2012) as, the extent to which an individual believes that he/she is obligated to bring about a constructive change - has been identified as a significant internal motivation that drives people to exhibit desired behavior (Zhu and Akhtar, 2019). While studying employee behavior, Liang et al., (2012) find that employees with high obligation for constructive change are highly likely to show voice behavior. According to Fuller et al., (2006), FOCC is a flexible psychological state that reflects a willingness to put in extra effort to bring about constructive change. Since, moral identity, driven from moral psychology, has been established to be a predictor of moral actions, based on self-consistency (Blasi, 2004; Hardy and Carlo, 2011). So, we invoke the self-consistency theory (Korman, 1970). This will help us explore the role of FOCC as the underlying mediating mechanism through which moral identity translates into promotive and prohibitive voice behaviors on social media. Specifically, we expect that individuals' moral identity first enhances their felt obligation for bringing about constructive change, which then motivates them to exhibit promotive and prohibitive voice on social media to be consistent with their self-image of being a moral person.

We also argue that even though moral identity, via enhanced FOCC, leads a person to engage in social media constructive voice behaviors, not everyone gets involved in voicing on social media. Some individuals, though high in moral identity are less likely to voice on social media to avoid an online debate or possibly arising differences with other social media users because of their voicing. Individuals who are ready to involve in such situations online are more likely to voice their concerns on social media. Hence, we consider the moderating role of a personality trait i.e., proactive personality - where proactive individuals are those who 'identify opportunities and act on them, show initiative, take action and persevere until meaningful change occurs' (Crant, 2000, p. 439). As such, in OB literature, proactive personality has been found to affect prosocial behaviors such as organizational citizenship behaviors (Li et al., 2010). In other words, we reason that the mediation effect of FOCC in the positive relationship between moral identity and promotive-prohibitive forms of constructive voice would be stronger for individuals with high proactive personality than of those with low proactive personality.

The research setting for this study focuses on social media sites. We concentrate particularly on constructive voice behaviors on SNSs (such as Facebook, Twitter, Instagram, LinkedIn, etc.) for two main reasons: (1) SNSs are the most widely used social media technology with just Facebook having 2.23 billion monthly active users (Statista, 2019). Due to the large number users and greater reachability, users are very likely to engage in voice behaviors on SNSs; 
(2) SNSs have a variety of technology-mediated features. This allows users to voice their concerns in multiple ways such as text (status messages/tweets, etc.) updates, photos posting, video posting (recorded or live broadcast), in public/private groups, as well as on business pages. For instance, the user could share their concerns on their personal page, or on a group page or even on a businessrun page with respect to any ethical, societal, or environmental matters.

The paper proceeds as follows. The next section discusses the theoretical framework of this research as well as the hypotheses development. The subsequent sections present the methodology, data analysis, and results. The paper concludes by presenting the discussion on research findings, limitations, and directions for future research.

\section{Theoretical Framework}

\section{Self-Consistency Theory}

Self-consistency theory, which is based on cognitive consistency (Festinger, 1957), suggests that individuals are motivated to indulge in behaviors consistent with their overall self-views, so that they can maintain a cognitive consistency between their attitudes and behaviors (Korman, 1970). In this regard, Korman (1970) argues that the behavioral responses of individuals are a strong reflection of their desire to establish a cognitive consistency toward their self-image. Therefore, both high self-esteem and low self-esteem individuals depict behaviors to preserve selfviews, such that, high self-esteem individuals maintain positive self-views (e.g., self-enhancement behaviors), while low self-esteem individuals preserve negative self-views (e.g., self-protective behaviors) (Crocker and Park, 2004).

Hardy and Carlo (2005) highlight the central role of self in moral actions. Blasi (1984) suggests that when one's self is based on moral concerns, this motivates an individual to engage in moral behaviors which are prosocial in nature, while he/she may engage in self-protective behaviors (such as withholding citizenship behaviors) if the self-perception is negative (Wu et al., 2018). Hence, Blasi (1984) suggests moral judgments are very likely to result in moral behaviors, especially if they are based on a person's moral identity and driven because of his/her selfconsistency. Shao et al. (2008, p. 518) put this as, "it is the self-importance of this [moral] identity, or the relatively enduring association between a person's sense of self and the mental representation of his or her moral character, coupled with the desire to maintain self-consistency that links moral identity to moral action."

Based on the theory of self-consistency, Winterich et al. (2013) suggest that the two dimensions of moral identity (i.e., internalization and symbolization) are predictors of prosocial motivation. We argue that the desire to be consistent with oneself is an important source of motivation for an individual (Blasi, 1984). It has been suggested that the individuals having a higher moral identity are more likely to indulge in prosocial behaviors since depicting such behaviors is consistent with their belief of how a moral person would act (Winterich et al., 2013). Blasi (1984) argues that individuals with high moral identity feel a need to maintain self- 
consistency between their behavior and moral identity. However, if there is an inconsistency (i.e., they do not engage in prosocial behavior when they should have), it can lead to psychological distress. Therefore, centered on self-consistency theory, we propose that individuals with high moral identity are very likely to act prosocially on social media and this is because they feel an obligation to do so. Hertz and Krettenauer (2016) stress that prosocial behaviors, are less influenced by external factors and hence less obligatory and therefore, are more reflective of an individual's actual moral identity. Hence, considering voice behavior a prosocial behavior, we invoke self-consistency theory to explore how moral identity predicts social media voice behavior of individuals. Accordingly, self-consistency theory serves as a key to building relationships between constructs in the proposed model. Following we discuss constructive voice on social media in further detail.

\section{Constructive Voice on Social Media}

The advent of social media has entirely changed the way people interact online and has enabled new forms of personalized social engagement (Kizgin et al., 2018) which does not need any significant organizational resources (Bennett and Segerberg, 2012). SNSs such as Facebook make it very easy for their users to generate content such as posting text, videos, and photos, etc. Skoric et al. (2016) argue that this user-generated content creates new opportunities for discussions, debate, and deliberation for social change. Many active users of social media take advantage of this opportunity to "be heard" by others and hence engage in voicing. Cappellini, Kravets \& Reppel (2018) emphasize on the importance of hashtags on social media as not only markers, but identifying them as amplifiers of issues important for wider public to generate discussions. They studied the case of the hashtag \#ShoutYourAbortion where people voiced about this socio-political issue and gained international attention. Miles and Mangold (2014) state that several social media websites are specifically created for people to voice about social change, whether its condemning a harmful practice or promoting social good. Many media companies request people (on social media) to send videos or photos of 'issues' around them that need correction or improvement. However, people also tend to post such content on their personal pages or profiles/timelines to generate debate or discussion with their followers to reach a consensus. Hence, the opportunity to reach a very large audience and hence making people aware of harmful practices in society or promoting social good - in an attempt to initiate social change - by a social media post, photo, or video has enabled people to engage in constructive voice on social media. Such attempts, by social media users, to bring a social change are prosocial in nature. Provided that voice behavior is largely studied in OB literature, there have been a number of studies recognizing voice as form of prosocial behavior and hence prosocially motivated (Dyne et al., 2003; Dyne and LePine, 1998; Liang et al., 2012). In a meta-analysis, (2011) Morrison argues that of the 13 identified prosocial behaviors in OB literature, two reflect voice behavior suggesting organizational improvements or objecting to improper procedures.

In the context of social media voicing, deriving from OB literature (Chamberlin et al., 2017; Morrison, 2014, 2011), we define online promotive and prohibitive voice behaviors, respectively 
as (1) the expression or sharing of new ideas on social media to improve the status quo; such as suggesting ways in which society can perform better in the future, and (2) the expression or sharing of concerns on social media about social issues and practices that, if remain unnoticed, could harm the society. Liang et al. (2012) argue that both are the forms of constructive voice behavior that challenges the existing status quo and bring constructive change in the community as a whole. However, promotive voice deals with realizing ideas and opportunities and is primarily futureoriented, i.e., suggesting ways to improve in the future (Liang et al., 2012). On the other hand, prohibitive voice is intended to stop or prevent harm, which has both past and future orientation such as to call attention to issues potentially harmful to the existing status quo or that are potentially harmful to the society (Liang et al., 2012). However, both forms of voice behavior are prosocial since they are constructive in nature and are discretionary (Morrison, 2011).

Although both promotive and prohibitive forms of voice are the forms of constructive voice behaviors that are inherently derived from a need to challenge the status quo - offering innovative ideas to bring constructive change and showing concerns for past or ongoing problems that, if left unchecked, could harm the organization/society (Liang et al., 2012; Morrison, 2014) - the way they do this is different. Promotive voice is future-oriented and positive in tone, and thus, is likely to be recognized and interpreted by others as a positive behavior. Prohibitive voice, on the other hand, is past-oriented, raising concerns over harmful work-related issues that have affected (or could affect) the organization/society badly, and is more negative in tone. It is less certain, therefore, that others will always interpret these behaviors positively, due to the heightened potential for interpersonal conflict and negative emotions that may stem from these contributions (Arain et al., 2019). These characteristics of promotive and prohibitive forms of voice make them distinct from similar other prosocial constructs like civic engagement and civic virtue, which are not necessarily derived from the need for challenging the status quo even at the cost of causing interpersonal conflict and negative emotions (Arain et al., 2019; Mowbray et al., 2015). Moreover, Goetz and Jenkins (2005) argue that voice has intrinsic value since it is good for people to feel free in expressing their beliefs and preferences and plays a significant role in facilitating communities to collectively reach the standards.

While, the literature on constructive voice behavior has explored a number of antecedents of promotive and prohibitive voice highlighting dispositional, emotional, attitudinal, and contextual factors [cf. (Chamberlin et al., 2017)], social media voice behavior seems to have been overlooked in voice or even in social media literature. A number of studies have acknowledged social media as a new medium of employee voice and how they use it to talk about work-related issues [e.g., (Holland et al., 2016; Martin et al., 2015; Miles and Mangold, 2014)], but the public use of social media in voicing societal concerns is yet to be explored. Hence, this study attempts to lay the groundwork in exploring the antecedents of constructive voicing on social media. To explain this phenomenon, based on the self-consistency theory, we focus on individual's moral identity as a potentially important predictor of promotive and prohibitive forms of constructive voice on social media. 


\section{Moral Identity}

Moral behavior is defined as behavior that is socially responsive to the needs of others (Reed et al., 2007). Moral identity refers to a person's deeply rooted self-conceptualization of what he/she is, which is a self-regulatory mechanism that motivates moral behavior (Erikson, 1964). For instance, Reed et al. (2007) explain from a marketing perspective that a consumer's moral identity is an exemplar of the traits that he/she holds in his/her mind of what a moral person possesses (such as being kind, honest, loving, showing concern or empathy for others, helping strangers, and engaging in charitable behaviors). They further argue that a consumer's moral identity influences his/her choices and actions that depict his/her socially responsible behavior. However, as López et al. (2017) argue, individuals are not just consumers and the individuals' behavior has exceeded beyond economic exchange and consumption. Therefore, individuals as citizens feel not only socially responsive to mere consumptions but also to other aspects of everyday life on ethical, environmental, and societal matters. Hence, in this study, we focus on the moral identity of individuals as members of the society.

Aquino and Reed (2002) further categorized moral identity into private (i.e., internalization) and public (i.e. symbolization) forms of moral identity. The internalization form of moral identity consists of the moral traits that are central to the self-concept; whereas, the symbolization form consists of the moral traits that are reflected in one's actions in the world (Aquino \& Reed II, 2002). Researchers [e.g., (Aquino et al., 2009; Ding et al., 2018; Leavitt et al., 2016)] studying OB have established a positive relationship between employees' moral identity and their prosocial and ethical behaviors. Taking a lead from this, our study attempts to extend and suggest that an individual's moral identity affects his/her voice behavior in the social media world. In the following section, we present our arguments on how an individual's moral identity is related to social media voicing.

\section{Moral Identity and Social Media Voicing}

López et al. (2017) argue that with respect to moral and ethical behavior, there is an excessive focus on consumerism, whereas, there is a dire need to acknowledge and address various other issues related to an individual's everyday life. Hence, they propose that individuals should be morally responsible to generate positive impacts on their social, environmental, and economic environment. This could be in the form of prosocial behavior, such as constructive voicing.

While differentiating in-role behaviors from extra-role behaviors, Dyne and LePine (1998) identify voice as an extra-role prosocial behavior. They argue that voice is a promotive behavior that focuses on constructive challenges rather than just criticizing, by making innovative suggestions for change (Dyne and LePine, 1998). In a meta-analytic study of 111 studies, analyzing the relationship between moral identity and moral behavior, Hertz and Krettenauer (2016) found that moral identity - both in internalization and symbolization forms - is a significant predictor of prosocial behaviors. The relationship has been confirmed in both correlational and experimental studies (Gotowiec and Mastrigt, 2019; Hardy et al., 2015). 
To fully explain this relationship, we invoke the self-consistency theory (Korman, 1970). The proponents of self-consistency theory (Pierce and Gardner, 2004) argue that individuals' tend to be consistent with their self-image by engaging in those behaviors that reinforce that self-image. Drawing this core tenet of self-consistency theory, the social-cognitive view of moral identity argue that an individual's moral identity motivates him/her to engage in those attitudes and behaviors that are consistent with his/her moral identity (Aquino et al., 2009; Aquino and Reed, 2002). For instance, Reed and Aquino (2003) argue that, once individuals' moral identity is created and strengthened, they would then tend to be consistent with that moral identity by enlarging their circle of moral regard, such as when one feels morally obliged to take care of the interests of other stakeholders (Reed and Aquino, 2003). Accordingly, the extant research has highlighted the positive relationship between individuals' moral identity and their prosocial behaviors such as charity, volunteering, and showing greater concern for the larger community (Leavitt et al., 2016). In doing so, people high in moral identity internalization, feel a motivation to engage in prosocial actions, irrespective of the public nature of these acts. People high in moral identity symbolization realize themselves as social entities and, therefore, would engage in prosocial actions (to be acknowledged by others), which is consistent with how they see themselves as moral individuals (Winterich et al., 2013).

Constructive voicing on social media is self-motivated (internalized), unlike voicing in organizations, which may be triggered by peer pressure, but at the same time, it might be prompted if an individual hopes to generate conversations around his/her raised voice (symbolized) (e.g., by getting his/her text, photos and/or videos "liked" or "shared"). This implies that, on social media, an individual's moral identity can both be self-centered or publicly represented. Therefore, we argue that both internalization and symbolization forms or moral identity are predictors of an individual's social media voice behavior. Hence, in line with the above arguments, we present our first hypothesis:

H1: An individual's moral identity (internalization \& symbolization) is positively associated with his/her (a) promotive and (b) prohibitive social media voicing

The investigation of $\mathrm{H} 1$ would not be complete without exploring the potential underlying mechanism through which moral identity may positively influence social media voicing. For this purpose, below we propose FOCC as a mediator, by invoking self-consistency theory, and examine how moral identity translates into social media voice behavior.

\section{Mediation of Felt Obligation for Constructive Change (FOCC)}

González (2018) argue that one's obligation towards others is contingent upon one's selfconception which is basically one's moral identity. The depiction of prosocial behavior towards others or one's society, because of one's moral identity, is conditional to an induced sense of obligation. Lee at al. (2014) demonstrate that the level of prosocial moral behavior is higher, because of one's moral identity, when one feels a higher level of responsibility. Following the theory of self-consistency (Korman, 1970), an individual feels an obligation to indulge in prosocial 
behaviors such as constructive voice to be consistent with one's moral identity - both in internalized and symbolized form.

Constructive voice behavior arises from the psychological state of feeling responsible for constructive change, which is defined as "an individual's belief that he or she is personally obligated to bring about constructive change" (Morrison and Phelps, 1999, p. 407). According to Liang et al.'s (2012), individuals are continually under the influence of social norms which shape their attitudes and behaviors. These social norms can be either descriptive norms (such as others' perceptions of how to commonly behave in specific circumstances) or injunctive norms (such as others' perceptions of what is acceptable culturally (Schultz et al., 2007). However, most pertinent type of norm in predicting an individual's planned behavior directed towards other's benefits is the moral norm, which is defined as personal rules of conduct (Conner and Mcmillan, 1999). We argue that this is particularly valid in the case of someone engaging in prosocial behavior, as it is an extra-role behavior and not influenced by others' perceptions of what should be done in a particular situation or what is culturally accepted. Hence, constructive change-oriented behavior and feeling an obligation to bring about a change and correcting problems is pertinent to a person's moral identity. In a study investigating SNSs users' prosocial behaviors, Kuem, Ray, Siponen \& Kim (2017) argue that three types of mechanisms i.e., dedication-, constraint-, and obligationbased mechanism lead to prosocial behaviors on SNSs, however, dedication- and constraint-based mechanisms mainly emphasize on individual-oriented and economic factors, but the obligationbased mechanism is strongly associated to interpersonal and social issues.

According to Blasi (1984), when high moral identity individuals feel an inconsistency in their behavior and moral identity, this leads to psychological stress. Therefore, they feel an obligation to perform actions consistent with their moral identity. Zhu and Akhtar (2019) argue that, in the OB literature, two distinct but related theoretical perspectives have been identified by researchers to inspect voice behavior. The first perspective is related to a leader's (such as a supervisor) influence on his follower to speak up or voice, while the second viewpoint suggests there is a prosocial motivation that instigates an employee's intention to depict voice behavior (Morrison, 2014). The two perspectives are used in conjunction with each other as predictors of voice behavior (Tangirala and Ramanujam, 2012). However, we argue that in examining social media voice behavior, there is essentially no role existence of a leader, and individuals are rather prosocially motivated. Hence, we propose FOCC as a prosocial motivator that has an influence on an individual's social media voice behavior. Following, the above arguments, we propose the following hypothesis:

H2: FOCC mediates the relationship between an individual's moral identity and his/her social media voice behavior

Heretofore, we have discussed how people's moral identity, via FOCC, leads them to engage in social media voice behavior. However, while examining the antecedents of constructive voice behavior, it is also necessary to examine the boundary conditions for those antecedents 
(Venkataramani et al., 2016). Therefore, we examine proactive personality, as a boundary condition, for the mediation effect of FOCC in the relationship between moral identity and promotive-prohibitive voice behavior to explain when the relationship is stronger and when it is weaker.

\section{Moderation of Proactive Personality}

We argued that moral identity, through FOCC, motivates a person to voice on social media; however, we propose that not all individuals would engage in such behavior in a similar manner. Individuals who perceive that voicing on social media may lead to potential conflicts, or unnecessary debate with other social media users, may be less likely to voice. Hence, the proposed relationship would be dependent on an individual's personality traits, such as proactive personality. A proactive personality is a predisposition towards a personal initiative to create a favorable environment (Crant, 2000). Proactive individuals see themselves as someone who could avoid or handle such potential situations because of their online voicing. They are more likely to do so as compared to those who are not that proactive.

Prior voice research suggests that constructive voice depends on a variety of dispositions (e.g., Big Five Personality traits), implying that even in the same settings, some people may exhibit higher levels of voice than their counterparts may (Morrison, 2014). Of the dispositional and personalityrelated determinants of constructive voice, a proactive personality is one of the strongest predictors (Chamberlin et al., 2017). Proactive personality refers to an individual's inclination toward bringing about a change in his/her environment (Bateman and Crant, 1993). Other people, who would not feel such inclination, classified as passive and reactive, are likely to adapt to the environment. Bateman and Crant (1993) further argue that individuals with a proactive personality trait look for opportunities and take initiatives to bring about change. Proactive people look for opportunities, show initiative, take action and are persistent until they reach closure by bringing about change. Crant (2000) and Fuller et al. (2003) reason that such people tend to engage in general (e.g., challenging the status quo) and contextual (e.g., career management) proactive behaviors.

Fuller and Marler (2009) suggested that proactive personality is an important predictor of individual behavior since this attribute is somewhat ungoverned by situational and environmental changes. Therefore, researchers have been keen on exploring its theoretical applicability in

predicting proactive behaviors, such as organizational citizenship behavior and feedback-seeking behavior (Parker et al., 2006). In organizations, employees with proactive personalities are dynamically involved in finding a solution to organizational issues, which may not be a part of their formal job requirements. Furthermore, they tend to make use of interpersonal contacts to provide useful information needed by other employees (Thompson, 2005). Extending this to a societal level, therefore, it is likely that proactive individuals will voice their suggestions to instate constructive changes for the betterment of their society. Fuller and Marler (2009) established that proactive personality is significantly associated with voice behavior. Furthermore, the meta- 
analytical findings of Chamberlin et al. (2017) highlight that proactive personality is positively related to both promotive and prohibitive forms of constructive voice behaviors.

Thus, following these arguments and empirical findings, we argue that mediation effect of FOCC in the relationship between moral identity and both forms of constructive voice behaviors would be depending on one's proactive personality traits, such as the relationship is likely to be stronger for social media users with high proactive personality than those of with low proactive personality. We hypothesize the following relationships.

H3a: The mediation effect of FOCC, between moral identity and promotive voice on social media, is moderated by proactive personality such that it would be stronger for individuals with high proactive personality than those with low proactive personality.

H3b: The mediation effect of FOCC, between moral identity and prohibitive voice on social media, is moderated by proactive personality such that it would be stronger for individuals with high proactive personality than those with low proactive personality.

Figure 1 shows a graphical representation of our proposed model of research.

Figure 1

A proposed conceptual model of research

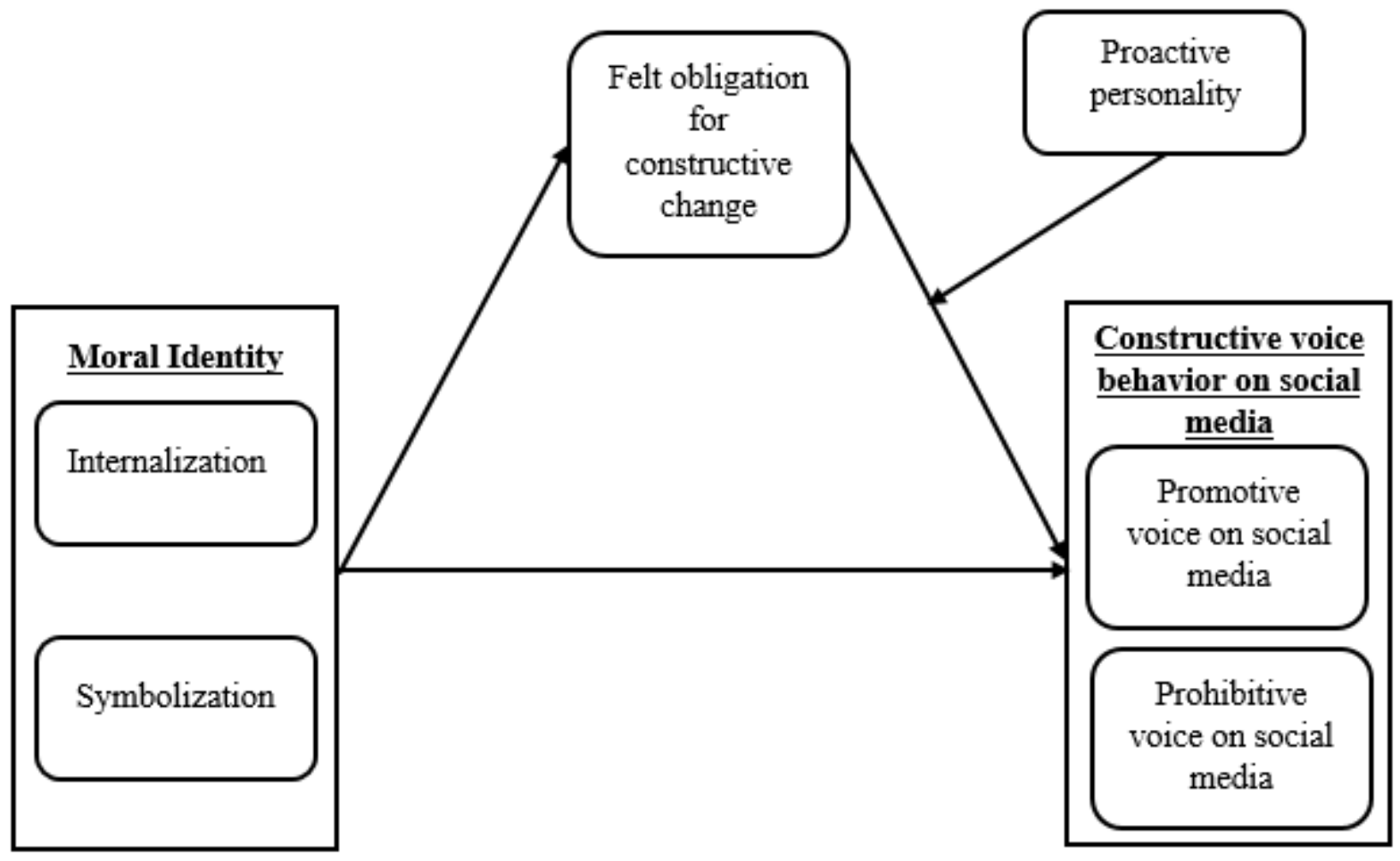




\section{Method}

\section{Survey Administration \& Research Context}

To examine the proposed hypotheses, data were collected from 229 SNSs users by hosting an online survey questionnaire. A link to the survey was posted in various diverse SNSs groups/pages such as on Facebook to ensure variance in the sample. While the survey link was posted on various SNSs (such as Twitter), posting on Facebook groups, makes it easier to administer as members of a page/group can increase the response rate. The survey link posted on social media had an additional information, requesting respondents to re-share the post on their feeds, which complimented the snowball sampling technique as suggested by Baltar and Brunet (2012). As such, response rate of surveys posted on social media sites is not possible without having a tracker link embedded with the survey link (McInroy, 2016). However, due to ethical considerations, and to keep the respondents (IP addresses) anonymous, the tracking link was not used. Unique tracking links compromise anonymity by providing a link to the respondent (Roberts and Allen, 2015). However, respondents were restricted to fill the survey only once based on their IP addresses. A cover letter was included to brief the participants about the study objectives, to guarantee their anonymity, and to ensure their consent to take the survey. Ethical approval and informed consent were sought before the respondents filled in the survey.

\section{Measures}

All measurement items were based on existing validated measures but were adapted according to the research setting for this study. Three $\mathrm{PhD}$ faculty members specializing in the relevant area were then used as judges in the evaluation of content validity of the adapted items. Appendix A provides a list of all measurement items and their sources. All the items were responded to on a five-point Likert scale ranging from not at all (1) to to a great extent (5).

The two dimensions of Moral Identity were measured by a ten-items scale developed by Aquino and Reed (2002) and further validated by Reed and Aquino (2003). Respondents were asked to visualize the kind of person who has good moral traits and answer questions related to internalized moral identity (internalization) and symbolized moral identity (symbolization) using a list of nine moral traits proposed by Aquino and Reed (2002). A sample item of the scale used to measure internalization is 'It would make me feel good to be a person who has these characteristics.' The internal consistency of this scale for this study was .90. A sample item of the scale used to measure symbolization is 'I often wear clothes that identify me as having these characteristics'. The internal consistency of this scale for this study was .87 .

Felt obligation for constructive change was measured by using a five-item scale adapted from Fuller et al. (2003). A sample item is 'I feel a personal sense of responsibility to bring about a change in society.' The internal consistency of this scale for this study was .90 
Promotive and prohibitive voice behaviors were measured by adapting a ten-item scale developed by Liang et al. (2012). A sample item of promotive voice is 'On social media, I proactively develop and make suggestions for issues that may influence the society.' A sample item of prohibitive voice is 'On social media, I advise others against undesirable behaviors that would hurt the society's well-being.' The internal consistency of this scale for this study was .95 for promotive voice and .93 for prohibitive voice.

Proactive personality was measured by using a six-item scale from Claes et al. (2005). A sample item is 'If I see something I don't like, I fix it.' The internal consistency of this scale for this study was .84.

Control variables: In order to reduce the possibility of spurious relationships based on unmeasured variables, we included four control variables, i.e., social media users' gender, education, age, and network size (number of online friends/followers) due to their likely effect on constructive voice behavior (Holland et al., 2016; Li et al., 2017).

\section{Sample Profile}

Overall, out of the 229 responses received, 3 were removed as being multivariate outliers, leaving us with 226 respondents on which further analyses were performed. Among the total 226 respondents, 77 (34.1\%) were males while 149 (65.9\%) were females. The sample had 43.8\% respondents below the age of 25 years, whereas $56.2 \%$ were 25 years or above. The number of social media friends/followers, termed as network size, was found to be less than 200 for $53.5 \%$ of the participants, whereas $46.5 \%$ had more than 200 friends in their network. As for the education level of participants, $46.5 \%$ were either undergraduate or below while $53.5 \%$ had at least a graduate degree. Majority $(85.8 \%)$ of users were frequent users of social media using it at least once every day. Asia and Europe based respondents hold the largest number of respondents with $62.2 \%$ and $26.2 \%$ of our sample, respectively with $11.4 \%$ from elsewhere. Table 1 provides the demographic information of the sample.

Table 1

Sample Demographics

\begin{tabular}{lll}
\hline Measure & Item $(\mathbf{n}=\mathbf{2 2 6})$ & Percentage \\
\hline Gender & Male & $34.1 \%$ \\
& Female & $65.9 \%$ \\
Age (in years) & $<25$ & $43.8 \%$ \\
& 25 or above & $56.2 \%$ \\
No. of social media friends/followers & $<200$ & $53.5 \%$ \\
& 200 or above & $46.5 \%$ \\
Education & Undergrad or below & $46.5 \%$ \\
\hline
\end{tabular}




\begin{tabular}{lll}
\hline & At least graduate & $53.5 \%$ \\
Frequency of social media use & Daily & $85.8 \%$ \\
& Twice a week & $4.40 \%$ \\
& Once a week & $4.00 \%$ \\
& Twice in a month & $2.70 \%$ \\
& Once in a month & $3.10 \%$ \\
\hline
\end{tabular}

\section{Results}

\section{Confirmatory Factor Analysis (CFA)}

Confirmatory factor analysis (CFA) was conducted using AMOS version 23 to confirm the proposed factor structure. Factor loadings for all items were well above the minimum threshold of 0.6 (Tabachnick and Fidell, 2013) except one item of the construct "proactive personality" which was dropped following the recommendation of Anderson and Gerbing (1988). We used the following combination of fit indices to evaluate model adequacy based on the recommendation of Hair et al. (2017): comparative fit index (CFI), Tucker-Lewis index (TLI), standardized root mean square residual (SRMR), and root mean square error of approximation (RMSEA). Following the recommendation of Hair et al. (2017), the base-line six-factor model was assessed to have a good fit with the data. In addition, as suggested by Bentler and Bonett (1980) two alternative models were tested and compared with our six-factor baseline model. The CFI and TLI scores above .90 and the SRMR and RMSEA scores below .07 are judged to confirm a good fitting model (Hair et al., 2017). The fit-indices and descriptions of the baseline and alternative models tested are provided in Table 2. The alternative models i.e., the four-factors model and the single-factor models had poor fit in comparison to the six-factor baseline model. Hence, we proceeded with further analysis.

Table 2

CFA Models' Fit Indices

\begin{tabular}{|c|c|c|c|c|c|}
\hline & Measurement (CFA) Model Comparison & $\overline{\text { SRMR }}$ & CFI & TLI & RMSEA \\
\hline Model 1 & $\begin{array}{l}\text { Six-factor baseline model, i.e., Internalization, } \\
\text { Symbolization, Felt obligation for constructive } \\
\text { change, promotive voice, prohibitive voice, proactive } \\
\text { personality }\end{array}$ & .07 & .95 & .95 & .05 \\
\hline Model 2 & $\begin{array}{l}\text { Four-factor alternative model, i.e., Internalization and } \\
\text { Symbolization were merged into one factor, and } \\
\text { promotive voice and prohibitive voice were merged } \\
\text { into one factor }\end{array}$ & .18 & .78 & .76 & .11 \\
\hline Model 3 & $\begin{array}{l}\text { Single-factor model, i.e., all measures were loaded on } \\
\text { a single latent factor }\end{array}$ & .17 & .62 & .59 & .10 \\
\hline
\end{tabular}

Note. $N=226$; $S R M R=$ Standardized root mean square residual; $C F I=$ Comparative fit index; $T L I=$ Tucker Lewis index; RMSEA = Root-mean square error approximation 
Prior to hypotheses testing, all measurement scales were subjected to reliability and validity tests. The results presented in Table 3 show that reliability values (i.e., Cronbach's alpha and composite reliability) for all variables are higher than the recommended threshold of 0.7 (Hair et al., 2017). Moreover, the average variance extracted (See Table 3) for each construct was higher than the recommended values of 0.5 (Hair et al., 2017). Therefore, the reliability and validity of each scale were established.

Table 3

Constructs' reliability validity

\begin{tabular}{lccc}
\hline Constructs & Alpha & CR & AVE \\
\hline Internalization & .90 & .93 & .72 \\
Symbolization & .87 & .90 & .66 \\
Felt Obligation for Constructive Change & .90 & .93 & .73 \\
Prohibitive Voice & .95 & .96 & .83 \\
Prohibitive Voice & .93 & .94 & .78 \\
Proactive Personality & .84 & .88 & .61 \\
\hline
\end{tabular}

Note. $N=226 ;$ Alpha $=$ Cronbach's Alpha; $C R=$ Composite reliability; $A V E=$ Average variance extracted; $I N T=$

Fornell and Larcker's (1981) suggested method was used to assess the discriminant validity among the constructs used in the proposed model (See Table 4). The diagonal values, representing the square roots of AVE for each of constructs, are higher in comparison to the values in the corresponding rows and columns, thus establishing the discriminant validity for all constructs.

Table 4

Inter-construct correlations and discriminant analysis

\begin{tabular}{|c|c|c|c|c|c|c|c|c|c|c|c|c|}
\hline Constructs & Mean & SD & 1 & 2 & 3 & 4 & 5 & 6 & 7 & 8 & 9 & 10 \\
\hline 1.Gender & .34 & .47 & & & & & & & & & & \\
\hline 2. Education & .54 & .50 & .01 & & & & & & & & & \\
\hline 3. Age & .56 & .49 & .03 & $.55^{* *}$ & & & & & & & & \\
\hline 4. Network size & .46 & .50 & -.05 & .06 & -.01 & & & & & & & \\
\hline 5. INT & 2.02 & .92 & -.01 & -.05 & .02 & -.12 & .85 & & & & & \\
\hline 6. SYM & 3.08 & .97 & $-.14 *$ & -.01 & .05 & .08 & .07 & .81 & & & & \\
\hline 7. FOCC & 3.18 & 1.07 & $-.13 *$ & $.17 * *$ & $.27 * *$ & .01 & $.28 *$ & $.38 * *$ & .85 & & & \\
\hline 8. PROMV & 2.48 & 1.21 & -.02 & .12 & $.24 * *$ & -.09 & $.40 * *$ & $.43 * *$ & $.68 * *$ & .91 & & \\
\hline 9. PROBV & 2.70 & 1.25 & -.01 & .10 & $.20 * *$ & -.06 & $.38 * *$ & $.32 * *$ & $.71 * *$ & $.83 * *$ & .88 & \\
\hline 10. PP & 3.68 & .79 & -.01 & .05 & .08 & .10 & .03 & $.39 * *$ & $.48 * *$ & $.47 * *$ & $.44 * *$ & .78 \\
\hline
\end{tabular}

Note. $N=226$; Diagonal values are square root of $A V E$ given in bold

$* *=p<0.01$ level; $*=p<0.05$ level.

INT = Internalization; $S Y M=$ Symbolization; FOCC =Felt obligation for constructive change; PROMV = Promotive voice; $P R O B V=$ Prohibitive voice; $P P=$ Proactive personality

Due to the self-reported questionnaire, there is a possibility of common method variance (CMV) as suggested by Podsakoff et al. (2003). To rule out the possible existence of CMV, we used both procedural and statistical measures. First, since the survey was administered online, a question randomization option was used to that helped shuffling the questions to be shown to respondents. Moreover, we ran Harman's single factor test with an exploratory factor analysis and un-rotated factor solution using SPSS. The result showed a total explained variance, by a single 
factor, of 39\%, which is well below the maximum threshold of 50\% as suggested by Podsakoff et al. (2003). We further confirmed the non-existence of CMV by conducting a common latent factor (CLF) test by comparing the standardized regression weights of CFA with and without CLF which was less than the maximum threshold of 0.20 (Serrano Archimi et al., 2018).

\section{Descriptive Statistics}

All the subsequent analyses including descriptive and moderated-mediation analyses were performed using SPSS version 23 PROCESS macro (Version 3), which allows measurement of such models and is less affected by the sample size (Hayes, 2012). Descriptive statistics were obtained including the means, standard deviations, and inter-construct correlations of our hypothesized model including control variables. The results show that the key independent and dependent variables correlate in the proposed directions, for example, internalization is positively correlated with both promotive $(\mathrm{r}=.40 ; \mathrm{p}<.01)$ and prohibitive voice $(\mathrm{r}=.38 ; \mathrm{p}<.01)$. Similarly, symbolization is also positively correlated to both promotive $(\mathrm{r}=.43 ; \mathrm{p}<.01)$ and prohibitive voice $(\mathrm{r}=.32 ; \mathrm{p}<.01)$. Consequently, we continued with the testing of our hypothesized model. Table 4 provides a summary of the inter-construct correlations of all constructs including control variables.

\section{Model Testing: Mediation Model (H1 and H2)}

To test hypotheses 1 and 2, in the next step, we tested all our proposed hypotheses using PROCESS macro for SPSS (Hayes, 2012). It may be noted that PROCESS macro gives un-standardized estimates; hence, standard error values are provided corresponding to each estimate. PROCESS macro uses a bootstrapping procedure to calculate the indirect effects via mediation. The Model 4 of PROCESS macro for SPSS was run four times, and then their results are synthesized in Table 5. Specifically, in the first two times, the direct and indirect (via FOCC) effects of internalized moral identity on promotive and prohibitive voices were, respectively, examined. While examining these effects, the effect of symbolized moral identity, along with the other control variables (i.e., gender, education, age, network size, and proactive personality), was statistically controlled. In the last two times, the direct and indirect (via FOCC) effects of symbolized moral identity on promotive and prohibitive voices were, respectively, examined. Similar to the first two times, the effect of internalized moral identity, along with the other control variables, was statistically controlled.

A summary of results depicting estimates, $t$ values, and the significance level of direct paths from the independent and control variables to dependent variables is provided in Table 5. The table also shows the estimates, $\mathrm{t}$ values, and significance of indirect paths from moral identity (i.e., internalization and symbolization) to social media constructive voice behaviors (i.e., promotive and prohibitive) via the mediating variable (i.e., FOCC). 
Table 5

Summary Regression Table of Mediation Model (H1 and H2)

\begin{tabular}{|c|c|c|c|c|c|c|c|c|c|c|c|c|}
\hline \multirow[b]{2}{*}{ Direct Effects } & \multicolumn{4}{|c|}{ FOCC (M) } & \multicolumn{4}{|c|}{ Promotive Voice (Y1) } & \multicolumn{4}{|c|}{ Prohibitive Voice (Y2) } \\
\hline & B & SE & $\mathbf{t}$ & $\mathbf{P}$ & B & $\overline{\text { SE }}$ & $\mathbf{t}$ & $\mathbf{P}$ & $\mathbf{B}$ & SE & $\mathbf{t}$ & $\mathbf{P}$ \\
\hline Constant & -.18 & .10 & -1.82 & .06 & -.06 & .08 & -.74 & .45 & -.02 & .08 & -.32 & .74 \\
\hline Gender & -.25 & .10 & -2.29 & .02 & .10 & .09 & 1.10 & .27 & .14 & .09 & 1.48 & .13 \\
\hline Education & .15 & .12 & 1.22 & .22 & .02 & .10 & .25 & .80 & -.02 & .10 & -.19 & .84 \\
\hline Age & $.37 * *$ & .12 & 3.03 & .00 & .18 & .10 & 1.69 & .09 & .08 & .10 & .73 & .46 \\
\hline Network Size & -.04 & .10 & -.46 & .64 & -.18 & .08 & -2.10 & .03 & -.11 & .08 & -1.28 & .20 \\
\hline PP & $.39 * *$ & .05 & 7.10 & .00 & $.17 * *$ & .05 & 3.35 & .00 & $.17 * *$ & .05 & 3.27 & .00 \\
\hline INT (X1) & $.24 * *$ & .05 & 4.73 & .00 & $.34 * *$ & .04 & 7.02 & .00 & $.34 * *$ & .05 & 6.43 & .00 \\
\hline SYM (X2) & $.19 * *$ & .05 & 3.45 & .00 & $.27 * *$ & .05 & 5.10 & .00 & $.15^{* *}$ & .05 & 2.67 & .00 \\
\hline FOCC & & & & & $.43 * *$ & .05 & 7.56 & .00 & $.55^{* *}$ & .05 & 9.63 & .00 \\
\hline
\end{tabular}

\begin{tabular}{lcccccc}
\hline $\begin{array}{l}\text { Indirect effects } \\
\text { via FOCC (M) }\end{array}$ & Effect $(\gamma)$ & BootSE & [LLCI, ULCI] & Effect $(\gamma)$ & BootSE & [LLCI, ULCI] \\
\hline INT & .10 & .02 & {$[.06, .16]$} & .13 & .03 & {$[.08, .20]$} \\
SYM & .08 & .03 & {$[.03, .14]$} & .10 & .03 & {$[.04, .18]$} \\
\hline
\end{tabular}

Note. $N$ = 226; PROCESS Model 4; $B=$ Unstandardized coefficients; PP = Proactive personality; FOCC = Felt obligation for constructive change; INT = Internalization; $S Y M=$ Symbolization, $L L C I=$ Lower limit confidence interval; ULCI = Upper limit confidence interval; **p<.001 
The results show that, even after controlling the effect of gender, education, age, network size of a social media user, and proactive personality, there is a significantly positive total effect of internalization on both promotive $(\mathrm{B}=.34 ; \mathrm{t}=7.02 ; \mathrm{p}=.000)$ and prohibitive voice $(\mathrm{B}=.34 ; \mathrm{t}=6.43$; $\mathrm{p}=.000)$. Symbolization also has a significantly positive total effect on both promotive voice $(\mathrm{B}=.27 ; \mathrm{t}=5.10 ; \mathrm{p}=.000)$ and prohibitive voice $(\mathrm{B}=.15 ; \mathrm{t}=2.67 ; \mathrm{p}=.000)$. Hypothesis 1 is therefore accepted.

As for the indirect effects, internalization has a significantly positive indirect effect on both promotive $(\gamma=.10,[.06, .16])$ and prohibitive $(\gamma=.13,[.08, .20])$ forms of constructive voice, via the mediation of FOCC. Furthermore, the indirect effect of symbolization is also positively significant on both promotive $(\gamma=.08,[.03, .14])$ and prohibitive $(\gamma=.10,[.04, .18])$ forms of constructive voice, via the mediation of FOCC. This implies that FOCC is a significant mediator in the relationship between a person's moral identity (internalized and symbolized) and his/her social media voice behavior (promotive and prohibitive). Hence, our proposed hypothesis, H2, is supported.

\section{Model testing: Moderated-Mediation model (H3a and H3b)}

To test hypotheses $3 \mathrm{a}$ and 3b, we used PROCESS model 14 (Hayes, 2012) for moderatedmediation analysis with 5000 bootstrap resamples. The results of the moderated-mediation analysis are presented in Table 6. Contrary to what was hypothesized, hypothesis $3 \mathrm{a}$, concerning the moderating effect of proactive personality on the mediation effect of FOCC in the relationship between internalization and promotive voice, is not supported. The results reveal that the interaction of FOCC and proactive personality has a non-significant moderating effect $(\mathrm{B}=.07$; $\mathrm{t}=$ $1.65, \mathrm{p}=.10$ ) on promotive voice.

On the other hand, hypothesis $3 \mathrm{~b}$, concerning the moderating effect of proactive personality on the mediation effect of FOCC in the relationship between internalization and prohibitive voice, is supported as hypothesized. The results show that the interaction of FOCC and proactive personality has a positive significant moderating effect $(B=.13 ; t=3.09, p=.002)$ on prohibitive voice. An examination of the conditional indirect effects of internalization on prohibitive voice on the three selected levels of proactive personality (i.e., $-1 \mathrm{SD}$, mean, and $+1 \mathrm{SD}$ ), reveals that the moderated-mediation relationship strengthens with increased levels of the moderator. The increasing values of moderated-mediation are: at $-1(\gamma=.10 ; \mathrm{S} . \mathrm{E}=.03 ; \mathrm{LL}=.05 \& \mathrm{UL}=.17)$, at mean $(\gamma=.14 ; \mathrm{SE}=.03 ; \mathrm{LL}=.08 \& \mathrm{UL}=.21)$, and at $+1 \mathrm{SD}(\gamma=.17 ; \mathrm{S} . \mathrm{E}=.04 ; \mathrm{LL}=.10 \& \mathrm{UL}=$ .25). Similarly, an examination of the conditional indirect effects of symbolization on prohibitive voice on the three selected levels of proactive personality (i.e., $-1 \mathrm{SD}$, mean, and $+1 \mathrm{SD}$ ), also reveals that the moderated-mediation relationship strengthens with increased levels of the moderator. The increasing values of moderated-mediation are: at $-1(\gamma=.14 ; \mathrm{S} . \mathrm{E}=.03 ; \mathrm{LL}=.08 \&$ $\mathrm{UL}=.21)$, at mean $(\gamma=.18 ; \mathrm{SE}=.03 ; \mathrm{LL}=.11 \& \mathrm{UL}=.25)$, and at $+1 \mathrm{SD}(\gamma=.23 ; \mathrm{S} . \mathrm{E}=.04 ; \mathrm{LL}=$ $.14 \& \mathrm{UL}=.32)$. Hence, we can conclude that hypothesis $3 \mathrm{a}$ is rejected whereas hypothesis $3 \mathrm{~b}$ is accepted which implies that proactive personality is an important boundary condition on the 
positive effect of moral identity (both internalization and symbolization) on an individual's prohibitive voice on social media but not for his/her promotive voice.

Table 6

Summary Regression Table of Moderated-Mediation Model (H3a and H3b)

\begin{tabular}{|c|c|c|c|c|c|c|c|c|}
\hline \multirow[b]{2}{*}{ Direct Effects } & \multicolumn{4}{|c|}{ Promotive Voice (Y1) } & \multicolumn{4}{|c|}{ Prohibitive Voice (Y2) } \\
\hline & B & SE & $\mathbf{t}$ & $\mathbf{P}$ & B & SE & $\mathbf{t}$ & $\mathbf{P}$ \\
\hline Constant & -.09 & .08 & -1.09 & .27 & -.08 & .08 & -1.00 & .31 \\
\hline Gender & .10 & .09 & 1.12 & .26 & .14 & .09 & 1.54 & .12 \\
\hline Education & .01 & .09 & .11 & .90 & -.04 & .10 & -.44 & .65 \\
\hline Age & .17 & .10 & 1.66 & .09 & .07 & .10 & .68 & .49 \\
\hline Network Size & -.17 & .10 & -1.97 & .04 & -.09 & .08 & -1.04 & .29 \\
\hline INT (X1) & $.22 * *$ & .04 & 4.82 & .00 & $.17 * *$ & .04 & 3.81 & .00 \\
\hline SYM (X2) & $.18 * *$ & .04 & 3.74 & .00 & .03 & .04 & .68 & .49 \\
\hline FOCC (M) & $.42 * *$ & .05 & 7.45 & .00 & $.54 * *$ & .05 & 9.56 & .00 \\
\hline $\mathrm{PP}(\mathrm{V})$ & $.18 * *$ & .05 & 3.47 & .00 & $.18 * *$ & .05 & 3.55 & .00 \\
\hline FOCC $x$ PP & .07 & .04 & 1.65 & .10 & $.13 * *$ & .04 & 3.09 & .00 \\
\hline $\begin{array}{l}\text { Conditional Indirect } \\
\text { effects } \\
\text { via FOCC }\end{array}$ & $\operatorname{Effect}(\gamma)$ & BootSE & \multicolumn{2}{|c|}{$\begin{array}{c}\text { [LLCI, } \\
\text { ULCI] }\end{array}$} & $\operatorname{Effect}(\gamma)$ & BootSE & \multicolumn{2}{|c|}{$\begin{array}{c}\text { [LLCI, } \\
\text { ULCI] }\end{array}$} \\
\hline $\begin{array}{l}\text { INT } \\
\text { Index of Moderated- } \\
\text { Mediation }\end{array}$ & .01 & .01 & \multicolumn{2}{|c|}{$[-.00, .04]$} & .03 & .01 & \multicolumn{2}{|c|}{$[.01, .06]$} \\
\hline$-1 \mathrm{SD}$ & .09 & .02 & \multicolumn{2}{|c|}{$[.04, .15]$} & .10 & .03 & \multicolumn{2}{|c|}{$[.05, .17]$} \\
\hline Mean & .11 & .02 & \multicolumn{2}{|c|}{$[.06, .16]$} & .14 & .03 & \multicolumn{2}{|c|}{$[.08, .21]$} \\
\hline$+1 \mathrm{SD}$ & .12 & .03 & \multicolumn{2}{|c|}{$[.07, .19]$} & .17 & .04 & \multicolumn{2}{|c|}{$[.10, .25]$} \\
\hline \multicolumn{9}{|l|}{ SYM } \\
\hline $\begin{array}{l}\text { Index of Moderated- } \\
\text { Mediation }\end{array}$ & .02 & .01 & \multicolumn{2}{|c|}{$[-.00, .05]$} & .04 & .01 & \multicolumn{2}{|c|}{$[.01, .08]$} \\
\hline$-1 \mathrm{SD}$ & .12 & .03 & \multicolumn{2}{|c|}{$[.07, .18]$} & .14 & .03 & \multicolumn{2}{|c|}{$[.08 .21]$} \\
\hline Mean & .14 & .03 & \multicolumn{2}{|c|}{$[.09, .21]$} & .18 & .03 & \multicolumn{2}{|c|}{$[.11, .25]$} \\
\hline$+1 \mathrm{SD}$ & .17 & .03 & \multicolumn{2}{|c|}{$[.10, .25]$} & .23 & .04 & \multicolumn{2}{|c|}{$[.14, .32]$} \\
\hline
\end{tabular}

Note. $N=226$; PROCESS Model 14; $B=$ Unstandardized coefficients; PP = Proactive personality; FOCC = Felt obligation for constructive change; INT = Internalization; SYM = Symbolization, $L L C I=$ Lower limit confidence interval; $U L C I=$ Upper limit confidence interval; $* * p<.001$

A synthesis of results of the proposed hypotheses is presented in Table 7

Table 7

Summary of hypotheses testing

\begin{tabular}{ll}
\hline Hypothesis & Conclusion \\
\hline H1 & Supported \\
H2 & Supported \\
H3a & Not Supported \\
H3b & Supported \\
\hline
\end{tabular}




\section{Discussion}

This study explores the role of moral identity, mediated by an individual's felt obligation for constructive change, in social media voice behavior. We proposed hypothesis H1 to examine the direct effects of moral identity (both internalized and symbolized) on social media voicing (both promotive and prohibitive voices), and $\mathrm{H} 2$ to examine the indirect, via FOCC, effects of both types of moral identity on both voice behaviors. The results of the study supported both $\mathrm{H} 1$ and $\mathrm{H} 2$. In addition, in $\mathrm{H} 3 \mathrm{a}$ and $\mathrm{H} 3 \mathrm{~b}$, we proposed that the mediation effects of FOCC between moral identity (both internalized and symbolized) and both promotive voice and prohibitive voice, respectively, are positively moderated by a proactive personality. However, the results of the study supported $\mathrm{H} 3 \mathrm{~b}$ but not $\mathrm{H} 3 \mathrm{a}$.

Social media voice behavior - derived from OB literature -- is prosocial in nature and is about sharing ideas on social media to improve the status quo or raising concerns about harmful practices in society. This implies bringing social change to address issues related to societal, environmental, and ethical practices. Voice behavior, by citizens, is essential for the continuous improvement of societies as they provide suggestions and feedback that can be worked upon (Botero and Van Dyne, 2009). As discussed earlier, no past studies have directly studied social media voice behavior for social change, rather voice behavior has been explored primarily in the organizational context i.e., employee voice behavior. However, Martin et al., (2015) note that social media is increasingly used as a tool for employee voice. Some researchers have explored prosocial behaviors on social media, such as engaging in charitable causes on social media (Paulin et al., 2014) and support for other user's social causes (Ferguson et al., 2013), but social media voice behavior has not been studied. Hence, a direct comparison of the results with past studies is unlikely; however, the results are consistent with the past research focusing on employees' moral identity and their voice behaviors.

Nevertheless, moral identity has been studied in contexts other than organizational settings and hence a number of studies have acknowledged the existence of a positive link between moral identity and prosocial behaviors, for instance, the meta-analytic study carried out by Hertz and Krettenauer (2016) establishes that moral identity was a predictor of prosocial moral behaviors. In a larger context, our study's findings support those of Gotowiec and Mastrigt's (2019) that both internalized and symbolized forms of moral identity are predictors of prosocial behavior for social change. However, this study departs from previous research in focusing on a more public form of prosocial behavior, i.e., voice behavior in public SNSs, which may influence more people than voice behavior within an organization or other contexts. In this regard, this research is in line with the findings of Hu and Jiang (2018) who found that people with high levels of moral identity are more likely to identify and voice about violations of socio-moral values. Their findings, however, are limited to the organizational setting, and the literature lacks research on voicing about societal matters on social media. Specifically, people identifying themselves as moral, tend to be consistent with their moral identity and engage in increasing their circle of moral regard by increasing their promotive and prohibitive forms of constructive voice on social media. 
Our results also reveal that the relationship between moral identity and social media voice behavior is explained by a FOCC drawing from the self-consistency theory. FOCC has been recognized as an important internal motivator that drives employees to engage in prosocial behavior towards their organizations (Fuller et al., 2006). This stance is also supported by Morrison (2014) and Zhu and Akhtar (2019) who identified FOCC as a strong predictor of constructive voice behavior in organizations. Our results are in line with these past findings and confirm that FOCC not only is a predictor of employee voice but also of voice behavior of social media users towards the society in general.

Finally, our results reveal that the relationship between moral identity and promotive voice behavior, mediated by FOCC, is not moderated by a social media user's proactive personality. However, this relationship for prohibitive voice behavior is moderated by proactive personality, such that the relationship gets stronger with higher levels of proactive personality. We argue that this might be due to the public nature of SNSs, and therefore, people take the advantage of using it as a medium to voice about matters that might be harmful or unethical for their society and surroundings. Since promotive voice behavior is about making suggestions for new projects or improvement in existing working procedures, and prohibitive voice behavior is more about "speaking up" against undesirable societal behaviors even if it would hurt the relationship with others, it takes a lot of courage to voice such concerns. Winterich et al. (2013) suggest that when prosocial behavior is likely to be recognized, moral identity symbolization tends to be a stronger predictor of prosocial behavior (Jennings et al., 2015). This stands true in social media, which is a platform with a high likelihood of voice recognition due to a large number of users. While our results indicate that internalized moral identity is a much stronger predictor of prosocial behaviors, yet they are much stronger when it comes to proactive individuals and specifically for prohibitive voice. Also, symbolized moral identity has been identified as a strong predictor of prosocial behavior related to outgroups (Crimston et al., 2016; Gotowiec and Mastrigt, 2019). Therefore, it takes a proactive personality to stand up against such harmful acts and it strengthens the relationship between moral identity and prohibitive voice behavior mediated by a FOCC.

In the past, researchers have found that even in the same context, some people would voice more significantly than others depending upon their personalities (Fuller and Marler, 2009; Xie et al., 2014). Our findings are in accordance with theirs, as they argue that individuals must assign cognitive resources to express their opinions. In the context of social media voicing, this cognition is even stronger as it requires feedback, arguments and may trigger a debate with one's social media followers. Generally, people tend to agree with an individual when they undertake promotive behavior. However, engaging in a prohibitive voice may require more proactive individuals to do so because they needs to standup for what they are voicing about.

\section{Practical Implications}

In practice, it is interesting how individuals tend to engage in voice behavior on social media. Bhimani et al. (2019) have stressed the need for studies to examine the value of social media directed at the societal level. They argue that such studies are very limited though some researchers 
have tried to address the issue. As quoted in a few examples in the introduction of the study, it is obvious that social media has given a voice to the people. Quazi et al. (2016) have opined that in consumer behavior literature, consumer social responsibility has been neglected, while, López et al. (2017) state that an individual is not only a consumer but as a member of society, his/her behavior encompasses much more which is his/her personal social responsibility. Our study takes the position that the moral identity of a person leads him/her to voice about societal concerns. From a practical point of view, individuals can take the social matters they care about to the online world to initiate debate and/or reach a consensus. In the past, governments, multinationals, and non-governmental organizations were the intuitions that had the reach and resources to initiate change. However, social media has provided an outlet for individuals where they can become agents of change by benefitting from the access social media has provided to reach a huge number of users, sometimes even on a global scale. The power of wisdom provided by social media to shape society's way of life and bring about social change is acknowledged in academic literature as well (Bhimani et al., 2019). Extending this, there may also be an opportunity for social activists or minority groups to take matters to the online world and let the world hear about it, using the power of social media. There exist cases around the world (such as citizen voice groups on Facebook), in which governments or social activist groups ask citizens to voice their concerns on dedicated social media pages, which can then be further be addressed. For instance, a social activist non-profit organization's Facebook page named Fixit ask citizens to highlight social, civic, and political issues faced by citizens, as mentioned on its Facebook page description.

In recent debates, proponents of technology use for societal advancement suggest citizencentric approaches to address societal problems. For instance, Trencher (2019) discusses the emergence of smart cities 2.0 and suggests that citizens have a central role in identifying problematic conditions in their surroundings. He identifies technology-based 'online reporting' tools as a way for local administrations to know citizens' concerns, allowing citizens to play a cocreative role by ensuring that these 'socio-technical; systems reflect citizen's concerns. Similarly, Sepasgozar et al., (2019) stress on the need of such socio-technical systems for local administrations to understand the needs of their citizens. Raford (2015) also builds on the application of the social web as a tool to create 'online foresight platforms' where citizens-based crowdsourcing can be triggered for strategic foresight. In this regard, public social media websites may serve as excellent tools for local administrations to 'listen' to the citizen's voice. Voicing on social media is often complemented by the use of hashtags (as discussed in the introduction), which has been recognized as a content sorting device (Cappellini et al., 2018; Yen and Dey, 2019). Therefore, public social media can serve as a very efficient tool in societal development and social media group managers may encourage group members to engage in such initiatives. We also suggest managers to moderate any unnecessary debates arising because of members posting their concerns.

It is also important to realize the power of social media in today's world that allows people to speak about matters they normally cannot. Thus, they can seek social support by taking matters on 
social media. This is particularly important for minority groups and a number of research studies have addressed the issue of minorities seeking social support through social media platforms. Overall, our findings can help governments, organizations, social activist groups to efficiently seek support by taking their concerns to social media.

\section{Theoretical Contributions}

Our study compromises of important theoretical contributions to both moral identity and voice literature specifically in the context where it is mediated by SNSs. First, this study is the first to investigate moral identity of social media users as an antecedent of social media voice behavior. Although, moral identity has been linked with prosocial behaviors by a number of researchers [e.g.,(Gotowiec and Mastrigt, 2019; Hardy et al., 2015)], yet again, prosocial behavior depiction, (e.g., voice), in the online context have been neglected. This study is an attempt to address this missing gap and does this by using the self-consistency theory perspective that is based on cognitive consistency. Given that our study aims at examining individuals' self-image, i.e., moral identity symbolization and internalization, as the antecedents of their voice behavior, the need for the "self-consistency" mechanism is adapted to explain the prosocial voice behaviors on social media. In this regard, the study extends the application of self-consistency theory, which is mainly applied in the psychology and OB literature, to a new context in SNSs. While, previous research has often used other theoretical bases to explain participation in SNSs such as gratification theory (Katz et al., 1973) or social identity theory (Tajfel, 1974), however, these theories are more relevant in explaining social/intergroup related antecedents of participation on SNSs. Given that our study aims at examining individuals' self-image, i.e., moral identity symbolization and internalization, as the antecedents of their voice behavior, the need for self-consistency explains why moral identity leads to voice behavior. Hence, SNSs based prosocial behaviors such as voice behaviors are explained from a new perspective.

The study establishes that as an individual (social media user) tends to be consistent with his/her moral identity, he/she then feels an obligation for a constructive change, which in turn is translated to his/her promotive and prohibitive voice on social media. Furthermore, Gotoweic and Mastrigt (2019) argue that both internalized and symbolized forms of moral identity have a synergized effect for the public but not private prosocial behavior. Most studies have explored these two constructs in an organizational context, which is not the same as SNSs. Altogether, our study makes significant a contribution to the moral identity literature by exploring public depiction of prosocial voice behavior because of both internalized and symbolized form of moral identity.

In addition, to the best of our knowledge, this is the first study that explores constructive voice behavior depiction in social media. Past research (Li et al., 2017; Lin et al., 2017; Mowbray et al., 2015) has largely addressed employee voice behavior in OB literature. A few studies, however, have acknowledged social media as a channel for employee voice [e.g., (Holland et al., 2016; Martin et al., 2015; Miles and Mangold, 2014)] and customer voice against firms [e.g., (Clark, 2013; Darroch, 2010)]. This suggests that social media sites, being public and social in nature, 
have a strong potential for people to voice their concerns. This study, therefore, contributes by addressing constructive voice behavior on social media from a societal perspective.

Another contribution of our study is with regard to the boundary condition in social media constructive voice behavior depiction as it establishes a moderating role of proactive personality. Even though, past research has established proactive personality as a predictor of voice behavior [e.g., (Xie et al., 2014)], our study further extends the literature by incorporating proactive personality of an SNS user as a moderating variable. Specifically, the study contributes by finding that while individuals depict promotive and prohibitive voice behavior, in SNSs, because of their moral identity, mediated by FOCC, the relationship with online prohibitive voice becomes stronger for proactive individuals, while it is not moderated for online promotive voice. In suggesting so, the study not only contributes to the literature related to moderators related to voice behavior but also differentiates the role of moderation in different types of social media voice depicted.

\section{Limitations and Future Research Directions}

Although this study has several theoretical and practical contributions as discussed above, it also has some limitations. First, the study incorporates cross-sectional design and considers individual's responses if they indulge in a voice behavior on social media. This could have the potential existence of $\mathrm{CMV}$; however, we have taken both procedural and statistical measures to rule-out the existence of CMV. It is also hard to establish causality with a cross-section design and future studies may take into consideration by analyzing a person's moral identity and matching it with their social media posts to confirm if they indulge in constructive voice behavior. This could be a more objective measure of voice behavior.

Second, as constructive voice behavior on social media triggers debate and suggests further actions to be taken; future studies can explore the possibility of such a behavior leading to civic engagement practices. Finally, other personality traits, apart from proactive personality, may play an important role in social media users' behaviors, and an exploration of such factors may be considered to gain an in-depth understanding of the phenomenon.

\section{Appendix A}

The following text was displayed to respondents before answering questions to internalization and symbolization:

For a moment, visualize in your mind the kind of person who has good moral characteristics,

e.g., Caring, Compassionate, Fair, Friendly, Generous, Hard-working, Hopeful, Honest, and

Kind. Imagine how that person would think, feel, and act.

When you have a clear image of what this person would be like, answer the following questions

Internalization (Aquino and Reed, 2002)

INT1 It would make me feel good to be a person who has these characteristics

INT2 Being someone who has these characteristics is an important part of who I am

INT3 I would not be ashamed to be a person who has these characteristics

INT4 Having these characteristics is really important to me 
INT5 I strongly desire to have these characteristics

Symbolization (Aquino and Reed, 2002)

SYM1 I often wear clothes that identify me as having these characteristics

SYM2 The types of things I do in my spare time (e.g., hobbies) clearly identify me as having these characteristics

SYM3 The kinds of books and magazines that I read identify me as having these characteristics

SYM4 The fact that I have these characteristics is communicated to others by my membership in certain organizations

SYM5 I am actively involved in activities that communicate to others that I have these characteristics

Felt obligation for constructive change (Fuller et al., 2006)

FOCC1 I feel a personal sense of responsibility to bring about change in society

FOCC2 It's up to me to bring about improvement in society

FOCC3 I feel obligated to try to introduce new procedures where appropriate

FOCC4 Correcting problems is my responsibility

Promotive voice (Liang et al., 2012)

PROMV1 On social media, I proactively develop and make suggestions for issues that may influence the society

PROMV2 On social media, I proactively suggest new projects which are beneficial to society

PROMV3 On social media, I raise suggestions to improve society's working procedures

PROMV4 On social media, I proactively voice out constructive suggestions that help the society reach its goals

PROMV5 On social media, I make constructive suggestions to improve the society's operations

Prohibitive voice (Liang et al., 2012)

PROBV1 On social media, I advise others against undesirable behaviors that would hurt the society's well-being

PROBV2 On social media, I speak up honestly about problems that might cause serious loss to society, even when others disagree

PROBV3 On social media, I dare to voice out opinions on issues that might affect the society' well-being, even if that would embarrass others

PROBV4 On social media, I dare to point out problems when they appear in society, even if that would hurt relationships with others

PROBV5 On social media, I dare to report coordination problems in society to the concerned people

Proactive personality (Claes et al., 2005)

PP1 If I see something I don't like, I fix it

PP2 No matter what the odds, if I believe in something I will make it happen

PP3 I love being a champion for my ideas, even against others' opposition

PP4 I excel at identifying opportunities 
PP5 I am always looking for better ways to do things

PP6 If I believe in an idea, no obstacle will prevent me from making it happen

\section{References}

Anderson, J., Gerbing, D.W., 1988. Structural Equation Modeling in Practice: A Review and Recommended Two-Step Approach. Psychol. Bull. 103, 411-423. https://doi.org/10.1037/0033-2909.103.3.411

Aquino, K., Freeman, D., Reed, A., Felps, W., Lim, V.K.G., 2009. Testing a social-cognitive model of moral behavior: the interactive influence of situations and moral identity centrality. J. Pers. Soc. Psychol. 97, 123-141. https://doi.org/10.1037/a0015406

Aquino, K., Reed, A., 2002. The self-importance of moral identity. J. Pers. Soc. Psychol. 83, 14231440.

Arain, G.A., Hameed, I., Crawshaw, J.R., 2019. Servant leadership and follower voice: the roles of follower felt responsibility for constructive change and avoidance-approach motivation. Eur. J. Work Organ. Psychol. 28, 555-565. https://doi.org/10.1080/1359432X.2019.1609946

Aryee, S., Walumbwa, F.O., Mondejar, R., Chu, C.W.L., 2017. Core Self-Evaluations and Employee Voice Behavior: Test of a Dual-Motivational Pathway. J. Manag. 43, 946-966. https://doi.org/10.1177/0149206314546192

Baltar, F., Brunet, I., 2012. Social research 2.0: virtual snowball sampling method using Facebook. Internet Res. 22, 57-74. https://doi.org/10.1108/10662241211199960

Bateman, T.S., Crant, J.M., 1993. The proactive component of organizational behavior: A measure and correlates. J. Organ. Behav. 14, 103-118. https://doi.org/10.1002/job.4030140202

Bennett, W.L., Segerberg, A., 2012. The Logic of Connective Action. Inf. Commun. Soc. 15, 739768. https://doi.org/10.1080/1369118X.2012.670661

Bentler, P.M., Bonett, D.G., 1980. Significance tests and goodness of fit in the analysis of covariance structures. Psychol. Bull. 88, 588-606. https://doi.org/37/0033-2909.88.3.588

Bhimani, H., Mention, A.-L., Barlatier, P.-J., 2019. Social media and innovation: A systematic literature review and future research directions. Technol. Forecast. Soc. Change 144, 251269. https://doi.org/10.1016/j.techfore.2018.10.007

Blasi, A., 2004. Moral Functioning: Moral Understanding and Personality, in: Moral Development, Self, and Identity. Lawrence Erlbaum Associates Publishers, Mahwah, NJ, US, pp. 335-347.

Blasi, A., 1984. Moral identity: Ils role in moral functioning, in: Morality, Moral Behavior, and Moral Development. John Wiley \& Sons, New York, pp. 128-139.

Botero, I.C., Van Dyne, L., 2009. Employee Voice Behavior: Interactive Effects of LMX and Power Distance in the United States and Colombia - Isabel C. Botero, Linn Van Dyne, 2009. Manag. Commun. Q. 23, 84-104.

Cappellini, B., Kravets, O., Reppel, A., 2018. Shouting on social media? A borderscapes perspective on a contentious hashtag. Technol. Forecast. Soc. Change. https://doi.org/10.1016/j.techfore.2018.07.016

Chamberlin, M., Newton, D.W., Lepine, J.A., 2017. A Meta-Analysis of Voice and Its Promotive and Prohibitive Forms: Identification of Key Associations, Distinctions, and Future Research Directions. Pers. Psychol. 70, 11-71. https://doi.org/10.1111/peps.12185 
Claes, R., Beheydt, C., Lemmens, B., 2005. Unidimensionality of Abbreviated Proactive Personality Scales across Cultures. Appl. Psychol. 54, 476-489. https://doi.org/10.1111/j.1464-0597.2005.00221.x

Clark, J., 2013. Conceptualising Social Media as Complaint Channel. J. Promot. Commun. 1.

Conner, M., Mcmillan, B., 1999. Interaction effects in the theory of planned behaviour: Studying cannabis use. Br. J. Soc. Psychol. 38, 195-222. https://doi.org/10.1348/014466699164121

Crant, J.M., 2000. Proactive behavior in organizations. J. Manag. 26, 435-462. https://doi.org/10.1016/S0149-2063(00)00044-1

Crimston, D., Bain, P., Hornsey, M., Bastian, B., 2016. (Moral Expansiveness: Examining Variability in the Extension of the Moral World. J. Pers. Soc. Psychol. 111.

Crocker, J., Park, L.E., 2004. The Costly Pursuit of Self-Esteem. Psychol. Bull. 130, 392-414. https://doi.org/10.1037/0033-2909.130.3.392

Darroch, J., 2010. Social Media: Giving a Voice Back to the People, in: Darroch, J. (Ed.), Marketing Through Turbulent Times. Palgrave Macmillan UK, London, pp. 30-38. https://doi.org/10.1057/9780230251182 4

Ding, W., Shao, Y., Sun, B., Xie, R., Li, W., Wang, X., 2018. How Can Prosocial Behavior Be Motivated? The Different Roles of Moral Judgment, Moral Elevation, and Moral Identity Among the Young Chinese. Front. Psychol. 9. https://doi.org/10.3389/fpsyg.2018.00814

Dyne, L.V., Ang, S., Botero, I.C., 2003. Conceptualizing Employee Silence and Employee Voice as Multidimensional Constructs*. J. Manag. Stud. 40, 1359-1392. https://doi.org/10.1111/1467-6486.00384

Dyne, V.L., LePine, J.A., 1998. Helping and Voice extra -role behaviors: Evidence of construct and predictive validity. Acad. Manage. J. 41, 108-119. https://doi.org/10.2307/256902

Erikson, E.H., 1964. Insight and responsibility: Lectures on the ethical implications of psychoanalytic insight, Insight and responsibility: Lectures on the ethical implications of psychoanalytic insight. W W Norton \& Co, New York, NY, US.

Ferguson, R., Paulin, M., Jost, N., Fallu, J.-M., Schattke, K.P., 2013. Millennials, Social Media, Moral Identity \& Support for Social Causes:Do Gender Differences Count? Acad. Manag. Proc. 2013, 12032. https://doi.org/10.5465/ambpp.2013.12032abstract

Festinger, L., 1957. A Theory of Cognitive Dissonance, Anniversary ed. edition. ed. Stanford University Press, Stanford, Calif.

Fornell, C., Larcker, D.F., 1981. Evaluating Structural Equation Models with Unobservable Variables and Measurement Error. J. Mark. Res. 18, 39-50. https://doi.org/10.2307/3151312

Fuller, J.B., Barnett, T., Hester, K., Relyea, C., 2003. A Social Identity Perspective on the Relationship Between Perceived Organizational Support and Organizational Commitment. J. Soc. Psychol. 143, 789-791. https://doi.org/10.1080/00224540309600432

Fuller, J.B., Marler, L.E., 2009. Change driven by nature: A meta-analytic review of the proactive personality literature. J. Vocat. Behav. 75, 329-345. https://doi.org/10.1016/j.jvb.2009.05.008

Fuller, J.B., Marler, L.E., Hester, K., 2006. Promoting felt responsibility for constructive change and proactive behavior: exploring aspects of an elaborated model of work design. J. Organ. Behav. 27, 1089-1120. https://doi.org/10.1002/job.408

Goetz, A., Jenkins, R., 2005. Reinventing Accountability - Making Democracy Work for Human Development. Palgrave Macmillan, UK. 
González, A.M., 2018. Practical Identity, Obligation, and Sociality. J. Soc. Philos. 49, 610-625. https://doi.org/10.1111/josp.12258

Gotowiec, S., Mastrigt, S. van, 2019. Having versus doing: The roles of moral identity internalization and symbolization for prosocial behaviors. J. Soc. Psychol. 159, 75-91. https://doi.org/10.1080/00224545.2018.1454394

Hair, J., Sarstedt, M., Ringle, C.M., Gudergan, S.P., 2017. Advanced Issues in Partial Least Squares Structural Equation Modeling, 1 edition. ed. SAGE Publications, Inc, Los Angeles.

Hardy, S.A., Bean, D.S., Olsen, J.A., 2015. Moral Identity and Adolescent Prosocial and Antisocial Behaviors: Interactions with Moral Disengagement and Self-regulation. J. Youth Adolesc. 44, 1542-1554. https://doi.org/10.1007/s10964-014-0172-1

Hardy, S.A., Carlo, G., 2011. Moral Identity: What Is It, How Does It Develop, and Is It Linked to Moral Action? Child Dev. Perspect. 5, 212-218. https://doi.org/10.1111/j.17508606.2011.00189.x

Hardy, S.A., Carlo, G., 2005. Identity as a Source of Moral Motivation. Hum. Dev. 48, 232-256. https://doi.org/10.1159/000086859

Hayes, A.F., 2012. PROCESS : A Versatile Computational Tool for Observed Variable Mediation , Moderation, and Conditional Process Modeling 1.

Hertz, S.G., Krettenauer, T., 2016. Does Moral Identity Effectively Predict Moral Behavior?: A Meta-Analysis. Rev. Gen. Psychol. 20, 129-149.

Holland, P., Cooper, B.K., Hecker, R., 2016. Use of social media at work: a new form of employee voice? Int. J. Hum. Resour. Manag. 27, 2621-2634. https://doi.org/10.1080/09585192.2016.1227867

$\mathrm{Hu}$, X., Jiang, Z., 2018. Employee-oriented HRM and voice behavior: a moderated mediation model of moral identity and trust in management. Int. J. Hum. Resour. Manag.

Jennings, P.L., Mitchell, M.S., Hannah, S.T., 2015. The moral self: A review and integration of the literature. J. Organ. Behav. 36, S104-S168. https://doi.org/10.1002/job.1919

Katz, E., Blumler, J.G., Gurevitch, M., 1973. Uses and Gratifications Research. Public Opin. Q. 37, 509-523.

Kizgin, H., Jamal, A., Rana, N., Dwivedi, Y., Weerakkody, V., 2018. The impact of social networking sites on socialization and political engagement: Role of acculturation. Technol. Forecast. Soc. Change. https://doi.org/10.1016/j.techfore.2018.09.010

Korman, A.K., 1970. Toward an hypothesis of work behavior. J. Appl. Psychol. 54, 31-41. https://doi.org/10.1037/h0028656

Kuem, J., Ray, S., Siponen, M., Kim, S.S., 2017. What Leads to Prosocial Behaviors on Social Networking Services: A Tripartite Model. J. Manag. Inf. Syst. 34, 40-70. https://doi.org/10.1080/07421222.2017.1296744

Leavitt, K., Zhu, L., Aquino, K., 2016. Good Without Knowing it: Subtle Contextual Cues can Activate Moral Identity and Reshape Moral Intuition. J. Bus. Ethics 137, 785-800. https://doi.org/10.1007/s10551-015-2746-6

Lee, S., Winterich, K.P., Ross, W.T., 2014. I'm Moral, but I Won't Help You: The Distinct Roles of Empathy and Justice in Donations. J. Consum. Res. 41, 678-696. https://doi.org/10.1086/677226

Leetaru, K., 2018. Is Social Media Empowering Or Silencing Our Voices? [WWW Document]. Forbes. URL https://www.forbes.com/sites/kalevleetaru/2018/10/08/is-social-mediaempowering-or-silencing-our-voices/ (accessed 6.19.19). 
Li, J., Liang, Q., Zhang, Z., 2017. Understanding How Leader Humility Evoke Employee Voice: An Identification Perspective. Acad. Manag. Proc. 2017, 11071. https://doi.org/10.5465/ambpp.2017.11071abstract

Li, N., Liang, J., Crant, J.M., 2010. The role of proactive personality in job satisfaction and organizational citizenship behavior: A relational perspective. J. Appl. Psychol. 95, 395404. https://doi.org/10.1037/a0018079

Liang, J., Farh, C.I.C., Farh, J.-L., 2012. Psychological Antecedents of Promotive and Prohibitive Voice: A Two-Wave Examination. Acad. Manage. J. 55, 71-92. https://doi.org/10.5465/amj.2010.0176

Lin, X., Chen, Z.-X., Hirst, G., Tse, H., Wei, W., Ma, C., 2017. Employee Voice and Leader Humility: The Perspective of Sense of Power. Acad. Manag. Proc. 2017, 11257. https://doi.org/10.5465/ambpp.2017.11257abstract

López, S.D., Marín, L.R., Ruiz de Maya, S., 2017. Introducing Personal Social Responsibility as a key element to upgrade CSR. Span. J. Mark. - ESIC 21, 146-163. https://doi.org/10.1016/j.sjme.2017.04.001

Martin, G., Parry, E., Flowers, P., 2015. Do social media enhance constructive employee voice all of the time or just some of the time? Hum. Resour. Manag. J. 25, 541-562. https://doi.org/10.1111/1748-8583.12081

McInroy, L.B., 2016. Pitfalls, Potentials, and Ethics of Online Survey Research: LGBTQ and Other Marginalized and Hard-to-Access Youths. Soc. Work Res. 40, 83-94. https://doi.org/10.1093/swr/svw005

Miles, S.J., Mangold, W.G., 2014. Employee voice: Untapped resource or social media time bomb? Bus. Horiz. 57, 401-411. https://doi.org/10.1016/j.bushor.2013.12.011

Morrison, 2014. Employee Voice and Silence. Annu. Rev. Organ. Psychol. Organ. Behav. 1, 173197. https://doi.org/10.1146/annurev-orgpsych-031413-091328

Morrison, E.W., 2011. Employee Voice Behavior: Integration and Directions for Future Research. Acad. Manag. Ann. 5, 373-412. https://doi.org/10.5465/19416520.2011.574506

Morrison, E.W., Phelps, C.C., 1999. Taking Charge at Work: Extrarole Efforts to Initiate Workplace Change. Acad. Manage. J. 42, 403-419. https://doi.org/10.2307/257011

Mowbray, P.K., Wilkinson, A., Tse, H.H.M., 2015. An Integrative Review of Employee Voice: Identifying a Common Conceptualization and Research Agenda. Int. J. Manag. Rev. 17, 382-400. https://doi.org/10.1111/ijmr.12045

News.com.au, 2017. Man's perfect takedown of racist woman at airport.

Parker, S.K., Williams, H.M., Turner, N., 2006. Modeling the antecedents of proactive behavior at work. J. Appl. Psychol. 91, 636-652. https://doi.org/10.1037/0021-9010.91.3.636

Paulin, M., J. Ferguson, R., Jost, N., Fallu, J.-M., 2014. Motivating millennials to engage in charitable causes through social media. J. Serv. Manag. 25, 334-348. https://doi.org/10.1108/JOSM-05-2013-0122

Pierce, J.L., Gardner, D.G., 2004. Self-Esteem Within the Work and Organizational Context: A Review of the Organization-Based Self-Esteem Literature. J. Manag. 30, 591-622. https://doi.org/10.1016/j.jm.2003.10.001

Podsakoff, P.M., MacKenzie, S.B., Lee, J.-Y., Podsakoff, N.P., 2003. Common method biases in behavioral research: a critical review of the literature and recommended remedies. J. Appl. Psychol. 88, 879-903. https://doi.org/10.1037/0021-9010.88.5.879 
Quazi, A., Amran, A., Nejati, M., 2016. Conceptualizing and measuring consumer social responsibility: a neglected aspect of consumer research. Int. J. Consum. Stud. 40, 48-56. https://doi.org/10.1111/ijcs. 12211

Raford, N., 2015. Online foresight platforms: Evidence for their impact on scenario planning \& strategic foresight. Technol. Forecast. Soc. Change 97, 65-76. https://doi.org/10.1016/j.techfore.2014.03.008

Reed, A., Aquino, K., Levy, E., 2007. Moral Identity and Judgments of Charitable Behaviors. J. Mark. 71, 178-193.

Reed, A., Aquino, K.F., 2003. Moral identity and the expanding circle of moral regard toward outgroups. J. Pers. Soc. Psychol. 84, 1270-1286.

Resce, G., Maynard, D., 2018. What matters most to people around the world? Retrieving Better Life Index priorities on Twitter. Technol. Forecast. Soc. Change 137, 61-75. https://doi.org/10.1016/j.techfore.2018.06.044

Roberts, L.D., Allen, P.J., 2015. Exploring ethical issues associated with using online surveys in educational research. Educ. Res. Eval. 21, 95-108. https://doi.org/10.1080/13803611.2015.1024421

Schultz, P.W., Nolan, J.M., Cialdini, R.B., Goldstein, N.J., Griskevicius, V., 2007. The constructive, destructive, and reconstructive power of social norms. Psychol. Sci. 18, 429434. https://doi.org/10.1111/j.1467-9280.2007.01917.x

Sepasgozar, S.M.E., Hawken, S., Sargolzaei, S., Foroozanfa, M., 2019. Implementing citizen centric technology in developing smart cities: A model for predicting the acceptance of urban technologies. Technol. Forecast. Soc. Change, Understanding Smart Cities: Innovation ecosystems, technological advancements, and societal challenges 142, 105116. https://doi.org/10.1016/j.techfore.2018.09.012

Serrano Archimi, C., Reynaud, E., Yasin, H.M., Bhatti, Z.A., 2018. How Perceived Corporate Social Responsibility Affects Employee Cynicism: The Mediating Role of Organizational Trust. J. Bus. Ethics 151, 907-921. https://doi.org/10.1007/s10551-018-3882-6

Shao, R., Aquino, K., Freeman, D., 2008. Beyond Moral Reasoning: A Review of Moral Identity Research and Its Implications for Business Ethics. Bus. Ethics Q. 18, 513-540. https://doi.org/10.5840/beq200818436

Skoric, M.M., Zhu, Q., Goh, D., Pang, N., 2016. Social media and citizen engagement: A metaanalytic review. New Media Soc. 18, 1817-1839. https://doi.org/10.1177/1461444815616221

Statista, 2019. Global social media ranking 2018 | Statistic [WWW Document]. Statista. URL https://www.statista.com/statistics/272014/global-social-networks-ranked-by-number-ofusers/ (accessed 2.16.19).

Tabachnick, B.G., Fidell, L.S., 2013. Using Multivariate Statistics, 6th ed. Pearson, Boston.

Tajfel, H., 1974. Social identity and intergroup behaviour. Inf. Int. Soc. Sci. Counc. 13, 65-93. https://doi.org/10.1177/053901847401300204

Tangirala, S., Ramanujam, R., 2012. Ask and You Shall Hear (but Not Always): Examining the Relationship Between Manager Consultation and Employee Voice. Pers. Psychol. 65, 251282. https://doi.org/10.1111/j.1744-6570.2012.01248.x

Thompson, J.A., 2005. Proactive Personality and Job Performance: A Social Capital Perspective. J. Appl. Psychol. 90, 1011-1017. https://doi.org/10.1037/0021-9010.90.5.1011

Time's Magazine, 2018. "Heartless, Cruel, Immoral." Every Major CEO Who Condemned Trump's "Zero Tolerance” Border Policy. Money. 
Trencher, G., 2019. Towards the smart city 2.0: Empirical evidence of using smartness as a tool for tackling social challenges. Technol. Forecast. Soc. Change, Understanding Smart Cities: Innovation ecosystems, technological advancements, and societal challenges 142, 117-128. https://doi.org/10.1016/j.techfore.2018.07.033

Venkataramani, V., Zhou, L., Wang, M., Liao, H., Shi, J., 2016. Social networks and employee voice: The influence of team members' and team leaders' social network positions on employee voice. Organ. Behav. Hum. Decis. Process. 132, 37-48. https://doi.org/10.1016/j.obhdp.2015.12.001

Winterich, K.P., Aquino, K., Mittal, V., Swartz, R., 2013. When moral identity symbolization motivates prosocial behavior: The role of recognition and moral identity internalization. J. Appl. Psychol. 98, 759-770. https://doi.org/10.1037/a0033177

Wu, L.-Z., Birtch, T.A., Chiang, F.F.T., Zhang, H., 2018. Perceptions of Negative Workplace Gossip: A Self-Consistency Theory Framework. J. Manag. 44, 1873-1898. https://doi.org/10.1177/0149206316632057

Xie, J., Chu, X., Zhang, J., Huang, J., 2014. Proactive personality and voice behavior: The influence of voice self-efficacy and delegation. Soc. Behav. Personal. 42, 1191-12001200. https://doi.org/10.2224/sbp.2014.42.7.1191

Yen, D.A., Dey, B., 2019. Acculturation in the social media: Myth or reality? Analysing socialmedia-led integration and polarisation. Technol. Forecast. Soc. Change 145, 426-427. https://doi.org/10.1016/j.techfore.2019.04.012

Zhu, Y., Akhtar, S., 2019. Leader trait learning goal orientation and employee voice behavior: the mediating role of managerial openness and the moderating role of felt obligation. Int. J. Hum. Resour. Manag. 30, 2876-2900. https://doi.org/10.1080/09585192.2017.1335338 